\title{
Microclimate and the Zoonotic Cycle of Tick-Borne Encephalitis Virus in Switzerland
}

\author{
C. BURRI, V. BASTIC, G. MAEDER, E. PATALAS, AND L. GERN ${ }^{1}$ \\ Institute of Biology, Laboratory of Eco-Epidemiology of Parasites, University of Neuchâtel, Emile-Argand 11, \\ 2000 Neuchâtel, Switzerland
}

\begin{abstract}
J. Med. Entomol. 48(3): 615-627 (2011); DOI: 10.1603/ME10180
ABSTRACT The focal distribution of tick-borne encephalitis virus (TBEV; Flaviviridae, Flavivirus) appears to depend mainly on cofeeding transmission between infected Ixodes ricinus L. nymphs and uninfected larvae. To better understand the role of cofeeding ticks in the transmission of TBEV, we investigated tick infestation of rodents and the influence of microclimate on the seasonality of questing I. ricinus ticks. A 3-yr study was carried out at four sites, including two confirmed TBEV foci. Free-living ticks and rodents were collected monthly, and microclimatic data were recorded. A decrease in questing nymph density was observed in 2007 , associated with low relative humidity and high temperatures in spring. One site, Thun, did not show this decrease, probably because of microclimatic conditions in spring that favored the questing nymph population. During the same year, the proportion of rodents carrying cofeeding ticks was lower at sites where the questing nymph density decreased, although the proportion of infested hosts was similar among years. TBEV was detected in $0.1 \%$ of questing ticks, and in 8.6 and $50.0 \%$ of larval ticks feeding on two rodents. TBEV was detected at all but one site, where the proportion of hosts with cofeeding ticks was the lowest. The proportion of hosts with cofeeding ticks seemed to be one of the factors that distinguished a TBEV focus from a non-TBEV focus. The enzootic cycle of TBEV might be disrupted when dry and hot springs occur during consecutive years.
\end{abstract}

KEY WORDS tick-borne encephalitis virus, Ixodes ticks, cofeeding, small mammals, microclimate

Tick-borne encephalitis (TBE) virus (TBEV) is a flavivirus affecting the human central nervous system (Dumpis et al. 1999) and is distributed from France through Eastern Europe, Russia, and Far East (Süss 2003). It was first clinically described by Schneider (1931) before it was known that Ixodes persulcatus Schulze (in the East of Russia) and Ixodes ricinus L. (in Western Europe) were the vectors of TBEV (Zilber 1939). Later, Pavlovsky (1947) proved zoonotic transmission involving small mammals such as field mice, Apodemus spp., and the bank vole, Myodes glareolus. These rodents are now known to be the main reservoirs for TBEV (Labuda et al. 1993b), but develop a short viremia and acquire antibodies against TBEV after $\approx 2 \mathrm{~d}$ (Kozuch et al. 1981). Immune hosts are generally considered to be noninfectious for ticks (Labuda et al. 1997), resulting in a low probability of transmission from rodents to ticks. The key to TBEV maintenance in nature is cofeeding nonviremic transmission of TBEV between infected nymphs and uninfected larvae on rodents, as proposed by Labuda and

\footnotetext{
The contents are the sole responsibility of the authors and do not necessarily reflect the views of the European Commission.

${ }^{1}$ Corresponding author: Institute of Biology, Laboratory of EcoEpidemiology of Parasites, Emile-Argand 11, 2000 Neuchâtel, Switzerland (e-mail: lise.gern@unine.ch).
}

Randolph (1999). Only rodents are known to support nonviremic transmission (Labuda and Randolph 1999). However, because larvae usually feed on small mammals and nymphs on medium-sized hosts (Tälleklint and Jaenson 1994), specific conditions seem to be required to allow larvae and nymphs to feed together on rodents. One of these conditions is the simultaneous questing of larvae and nymphs (Labuda and Randolph 1999) that is favored at the beginning of the year when temperatures rapidly exceed $10^{\circ} \mathrm{C}$, the minimal threshold for larvae to quest (Randolph 2004); nymphs become active at $7^{\circ} \mathrm{C}$ (MacLeod 1939). Another condition that improves the simultaneous feeding of larvae and nymphs (cofeeding) on rodents is dry climatic conditions, because low humidity forces nymphs to quest at lower levels in the vegetation than usual, bringing them to the same level as questing larvae (Randolph and Storey 1999) and thereby enabling them to exploit the same hosts.

The current study examines abiotic (temperature, relative humidity $[\mathrm{RH}]$, and saturation deficit $[\mathrm{SD}]$ ) and biotic (host range and host density) factors in a region in Switzerland where TBE cases have been reported to better understand focal TBEV maintenance and the importance of cofeeding transmission of TBEV under natural conditions. 


\section{Materials and Methods}

Our study was carried out at four sites, with similar beech grove mesophytic lowland vegetation located in the canton of Bern, Switzerland. Two of them were known TBE foci (Thun [ $46^{\circ} 43^{\prime} \mathrm{N}, 7^{\circ} 36^{\prime} \mathrm{E}, 642 \mathrm{~m}$ a.s.l.] and Belp [ $46^{\circ} 52^{\prime} \mathrm{N}, 7^{\circ} 30^{\prime} \mathrm{E}, 687 \mathrm{~m}$ a.s.l.]) and two, located in between, were not known as TBE foci (Kiesen [ $46^{\circ} 48^{\prime} \mathrm{N}, 7^{\circ} 34^{\prime} \mathrm{E}, 566 \mathrm{~m}$ a.s.l.] and Trimstein [ $46^{\circ} 53^{\prime} \mathrm{N}, 7^{\circ} 34^{\prime} \mathrm{E}, 620 \mathrm{~m}$ a.s.l.] ). Each site was $11-18 \mathrm{~km}$ apart. In Switzerland, an area is considered as a TBE focus if either three human cases have been reported to the Federal Office of Public Health or TBEV has been detected in ticks.

Questing I. ricinus Ticks and Microclimatic Conditions. Questing ticks were collected with a $1-\mathrm{m}^{2}$ white flag that was inspected for the presence of ticks at intervals of $5 \mathrm{~m}$ over a distance of $100 \mathrm{~m}$ within a 900-m perimeter. Tick collections took place once to twice per month from March (Thun and Belp) or June 2006 (Kiesen and Trimstein) to April 2009. All questing nymphs and adults were washed in $70 \%$ ethanol, dried, pooled from one to 10 nymphs and one to six males or females, and stored at $-20^{\circ} \mathrm{C}$ until tested for TBEV. Microclimatic data (air temperature at $60 \mathrm{~cm}$ and $\mathrm{RH}$ ) were taken with a thermohygrometer (Testo 615, S.A. Lonay, Switzerland) when ticks were collected. Data from air temperature at $60 \mathrm{~cm}$ and $\mathrm{RH}$ were used to calculate saturation deficit (SD) according to Randolph and Storey (1999) and Perret et al. (2000). We obtained additional data on macroclimate (monthly mean temperature and $\mathrm{RH}$ ) from Nofeln, a site close to the study area (http://www.agrometeo. $\mathrm{ch} / \mathrm{)}$, to relate these data to microclimatic data recorded at the study sites.

To gain more information on the presence of TBEV in questing ticks, additional questing ticks were collected outside the delimited perimeter (see above) from October 2006 to April 2009. Tick pools consisted of one to 20 nymphs and one to six males or females. Ticks were processed as described above.

Ticks on Rodents. Once per month from May 2006 in Belp and Thun and from June 2006 in Kiesen and Trimstein to April 2009, 50 wooden box traps (Czech trap model, http://members.vienna.at/shrew/trapping.html) were spaced at 5-m intervals inside each 900-m perimeter and were baited with seed and a piece of apple. The Department of Agriculture and Nature from Canton Bern approved the capture of rodents. For maintenance and all experimental procedures, the Department of Economy of Canton Neuchâtel delivered authorizations 1/2003 and $1 / 2006$. Traps were set at sunset and checked early the following morning. Captured rodents were brought into the laboratory identified, sexed, and caged individually over a pan of water until the feeding ticks dropped off. Rodents were then released at the exact trapping site. Engorged ticks were collected from the water, dried, identified, and stored. Because Ixodes trianguliceps ticks are difficult to maintain in the laboratory, they were stored as engorged ticks at $-20^{\circ} \mathrm{C}$, whereas I. ricinus ticks were kept in tubes at $98 \% \mathrm{RH}$ and room temperature until molt. Two months after their molt, live I. ricinus ticks were washed in $70 \%$ ethanol and stored at $-20^{\circ} \mathrm{C}$ until processed for TBEV detection. All I. ricinus ticks from rodents were analyzed by pools (one pool per tick stage per host) of one to 10 nymphs and one to six males or females for all sites except for Kiesen, where pools varied from one to 20 nymphs.

TBEV Detection. Ticks were tested for TBEV by real-time reverse transcription (RT)-polymerase chain reaction (PCR). To extract and purify RNA, pools of nymphal and adult ticks were crushed for 3 or $5 \mathrm{~min}$, respectively, in vials containing $300 \mu \mathrm{l}$ of TRIzol (Invitrogen Life Technologies, Basel, Switzerland) and a 3-mm ball using a mixer mill MM 300 (Retsch, Arlesheim, Switzerland). RNA from I. ricinus was isolated according to the Invitrogen protocol (Chomczynski and Sacchi 1987) with some modifications. Incubation time was 10 min for chloroform and isopropanol, and centrifugation time was $15 \mathrm{~min}$ for isopropanol and $6 \mathrm{~min}$ for ethanol. Samples were dried for 30-40 min, eluted in $30 \mu \mathrm{l}$ of water RNase free, stored at $-20^{\circ} \mathrm{C}$, and analyzed by real-time RT-PCR. RNA from I. trianguliceps was isolated with the Virus and Bacteria kit (Qiagen, Düsseldorf, Germany) with a robot QIAsymphony SP system (Qiagen), according to manufacturer (analyzed in Spiez Laboratory, Spiez, Switzerland).

RNA $(5 \mu \mathrm{l})$ was amplified in a $25 \mu \mathrm{l}$ real-time RTPCR mixture according to Schwaiger and Cassinotti (2003) using an iCycler (Bio-Rad, Reinach, BL, Switzerland) and consisting in $12.5 \mu$ l of reaction mix containing dNTPs $(0.04 \mathrm{mM}$ each $), 0.5 \mu \mathrm{l}$ of Superscript III Platinum Taq (Invitrogen, Basel, Switzerland; Superscript III Platinum One-Step quantitative system), $3 \mu \mathrm{M}$ primer F-TBE1, $0.6 \mu \mathrm{M}$ R-TBE1, and 0.8 $\mu \mathrm{M}$ for probe TBE. Strain Ljubljana II (kindly provided by P. de Mendonça, Institut für Vergleichende Tropenmedizin und Parasitologie, München, Germany) was used as positive control, and distilled water was used as a negative control.

Sequencing of NS5 Protein Gene of TBEV. Samples positive by real-time RT-PCR were confirmed by amplifying the nonstructural NS5 portion of the genome using primers described in Puchhammer-Stockl et al. (1995). Reaction mix for amplification was modified from Saksida et al. (2005). Before amplification, $10 \mu \mathrm{l}$ of RNA was transcribed into cDNA according to Invitrogen protocol. The first amplification was performed in a reaction volume of $50 \mu \mathrm{l}$ containing $5 \mu \mathrm{l}$ of Qiagen buffer $10 \times, 200 \mu \mathrm{M}$ each dNTP, $0.2 \mu \mathrm{M}$ each primer FSM-1 and FSM-2 (Puchhammer-Stockl et al. 1995), $1.5 \mathrm{U}$ per test of DNA Taq polymerase from Qiagen, and $10 \mu \mathrm{l}$ of cDNA. Amplification was performed in 40 cycles of amplification $\left(94^{\circ} \mathrm{C}, 30 \mathrm{~s} ; 40^{\circ} \mathrm{C}\right.$, $\left.30 \mathrm{~s} ; 72^{\circ} \mathrm{C}, 30 \mathrm{~s}\right)$ and $72^{\circ} \mathrm{C}, 5 \mathrm{~min}$ for the final elongation. The nested PCR was performed in a total volume of 50 $\mu \mathrm{l}$ with $2 \mu \mathrm{l}$ of the amplified DNA as template and 0.2 $\mu \mathrm{M}$ each inner primers FSM-1i and FSM-2i (Puchhammer-Stockl et al. 1995) (buffer, Taq polymerase, and dNTP, as described above). The nested PCR conditions were the same as described above, except for 
the hybridization temperature performed at $53^{\circ} \mathrm{C}$ for $30 \mathrm{~s}$. Amplified products were visualized on a $2 \%$ agarose gel stained with GelRed and visualized under ultraviolet light. The amplified TBEV products were processed with a purification kit (Promega AG, Dübendorf, Switzerland) and sent for sequencing to Microsynth (Balgach, Switzerland).

Host DNA Detection. To identify hosts on which nymphs had fed as larvae, additional questing I. ricinus nymphs were collected at the four sites during spring and summer in 2006 and 2008 (only 2008 for Thun). Host DNA was determined by PCR, followed by reverse line blotting, according to Humair et al. (2007). Before PCR, ticks were washed in $70 \%$ ethanol, dried, and stored at $-20^{\circ} \mathrm{C}$. To isolate host DNA, nymphs were washed in DNA Zap (Ambion, AB, Rotkreuz, Switzerland) for $3 \mathrm{~min}$, then rinsed in distilled water and processed, as described in Burri et al. (2007). Amplified host DNA was identified using the oligonucleotide probes described in Morán Cadenas et al. (2007b).

Statistical Analyses. All statistical analyses were calculated with S-Plus 7.0 and TIBCO Spotfire $\mathrm{S}^{+}$for Windows (Insightful, Seattle, WA). Descriptive statistics were used to follow questing tick phenology, as shown in Perret et al. (2003). Questing tick density was expressed as the number of ticks per $100 \mathrm{~m}^{2}$ and was calculated as an annual value called the cumulative tick density (CTD) (Eisen et al. 2003). This value was calculated by integrating the linearly interpolated curve of questing tick density over $1 \mathrm{yr}$ for $100 \mathrm{~m}^{2}$ (Jouda et al. 2004, Burri et al. 2007, Morán Cadenas et al. 2007b). To test mean infestation of rodents, we used a Mann-Whitney $U$ test. A $t$ test was used to test mean of rodents trapped/night by years and sites. The difference in the prevalence of rodents infested by ticks was tested by using a Fisher exact test or a Pearson $\chi^{2}$ test $\left(\chi^{2}\right)$. To test correlation between the number of I. ricinus larvae and nymphs infesting rodents, we used a Spearman rank correlation. The TBEV infection prevalence in ticks was expressed as the minimum infection rate per 100 tested (MIR) based on the assumption that at least one tick was positive within a positive pool.

\section{Results}

Seasonal Phenology of Questing Ticks. Overall, questing tick activity was observed on vegetation from February to November, displaying a unimodal pattern with nymphs and adults questing simultaneously (Fig. 1). Although larvae were observed questing during these months, they were only collected sporadically (Kiesen), or not at all (Thun), because the flagging collection procedure did not penetrate the vegetative canopy above their questing sites (Fig. 1).

In Switzerland, the winter 2006-2007 was the hottest recorded since 1864 and was followed by a hot spring (http://www.meteosuisse.admin.ch/web/fr/ meteo/actualite meteo/printemps 2007 extremement 0. html). The mean temperature in March, April, and May was $1^{\circ} \mathrm{C}$ warmer than in 2003 (previously the hottest spring since 1864). April had the warmest mean temperature, reaching $16^{\circ} \mathrm{C}$, with a maximum at $23^{\circ} \mathrm{C}$. In the study areas, the winter of $2006-2007$ was mild, and the spring of 2007 (April) was particularly dry and hot compared with 2006, 2008, and 2009 (Fig. 2). In 2007 , temperatures at $60 \mathrm{~cm}$ above soil reached $7^{\circ} \mathrm{C}$, the threshold temperature for nymphal activity, earlier than the other years (at some sites already at the end of January) (Fig. 3), allowing an earlier onset of nymphal questing activity (Fig. 1). Later, in April, temperature increased rapidly and remained between 20 and $25^{\circ} \mathrm{C}$ until August-September 2007 (Fig. 3). SD reached values above $10 \mathrm{mmHg}$ (maximum value 16.7 $\mathrm{mmHg}$ ) for almost $2 \mathrm{mo}$ (April and May) at three of four sites (except at Thun) (Fig. 3). At these three sites, April-May was usually the period when questing activity of nymphs was the highest (Fig. 1); however, in 2007, the lowest peak tick density and CTD were recorded when high SD values were observed (Table 1).

At Thun, although 2007 also was characterized by a hot and dry spring, in contrast to the other sites, temperatures never exceeded $23^{\circ} \mathrm{C}$ and were cooler compared with 2006 and 2008 (Fig. 3). SD reached high values (not higher than $12 \mathrm{mmHg}$ in 2007) for a shorter period than observed at the other sites ( $3 \mathrm{wk}$ in May), but was lower than in $2006(18.2 \mathrm{mmHg}$ ) (Fig. 3), which may explain why in 2007, Thun, in contrast to the three other sites, had higher peak tick density and CTD values for nymphs (Table 1).

Ticks on Rodents. During the whole study, 819 rodents were captured, as follows: Apodemus flavicollis $(n=160)$, Apodemus sylvaticus $(n=225)$, Apodemus spp. $(n=2)$, and M. glareolus $(n=432)$. Overall, the most rodents were trapped at Kiesen (0.14 rodent/ trap/night), followed by Trimstein ( 0.1 rodent/trap/ night), Thun ( 0.08 rodent/trap/night), and Belp (0.07 rodent/trap/night), but the difference was not significant ( $t$ test, $P>0.05)$. Trapping sessions were more successful in 2007 (0.2 rodents/trap/night) compared with 2008 (0.1 rodents/trap/night) and 2006 (0.06 rodents/trap/night) $(t$ test, 2006/2007, $P<0.001$, $2007 / 2008, P=0.001$ ).

Overall, a total of 7,718 I. ricinus ticks was collected from rodents (7,306 larvae and 412 nymphs). I. trianguliceps was observed at all sites (11 larvae, one nymph, and six females) infesting $11 \mathrm{M}$. glareolus and three A. sylvaticus. The percentage of infested rodents that carried at least one tick was $71.7 \%$ (587/819) (Table 2), with the highest percentage at Kiesen $(74.9 \%, 221 / 295)$, followed by Thun $(74.6 \%, 126 / 169)$, Belp $(69.1 \%, 103 / 149)$, and Trimstein $(63.4 \%, 130 /$ 205) $\left(\chi^{2}, P>0.05\right)$.

The seasonal infestation pattern of rodents by larvae and nymphs did not match the seasonal questing activity of adult and nymphal ticks (Figs. 1 and 4). Larvae were observed on rodents from FebruaryMarch to November, sometimes without interruption during the winter months, e.g., Kiesen during winter 2006-2007, when questing ticks were not active on vegetation. 


\section{Thun}

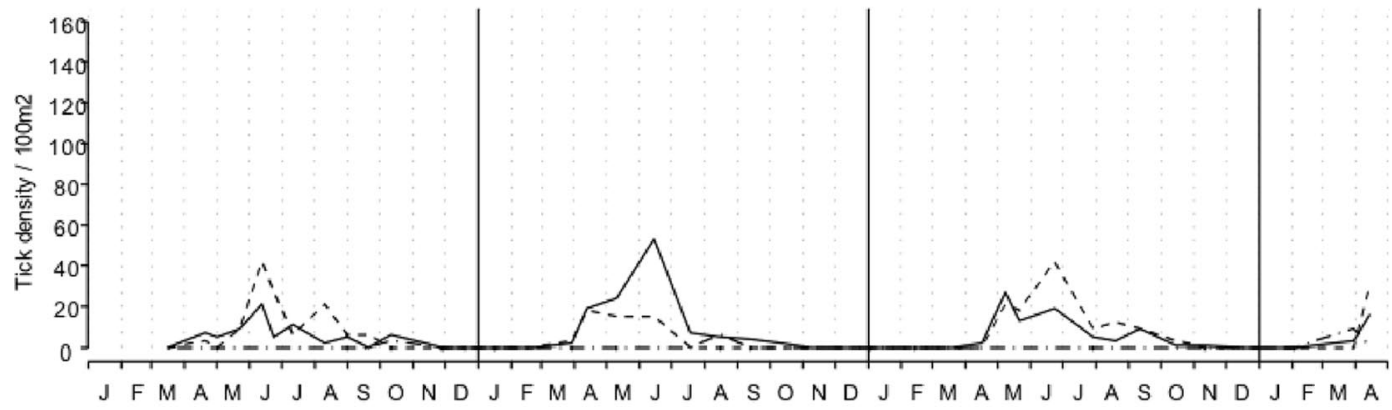

\section{Belp}

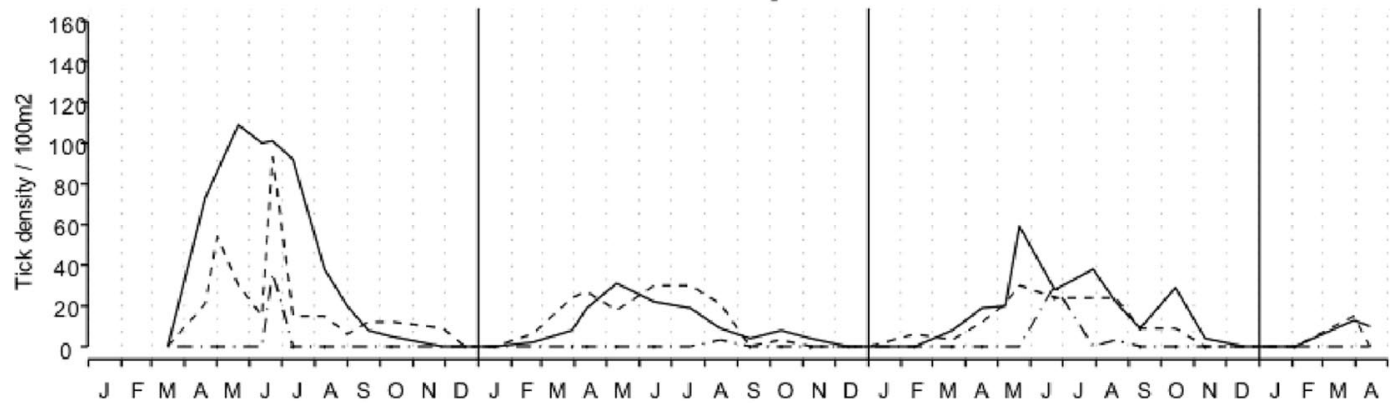

\section{Kiesen}

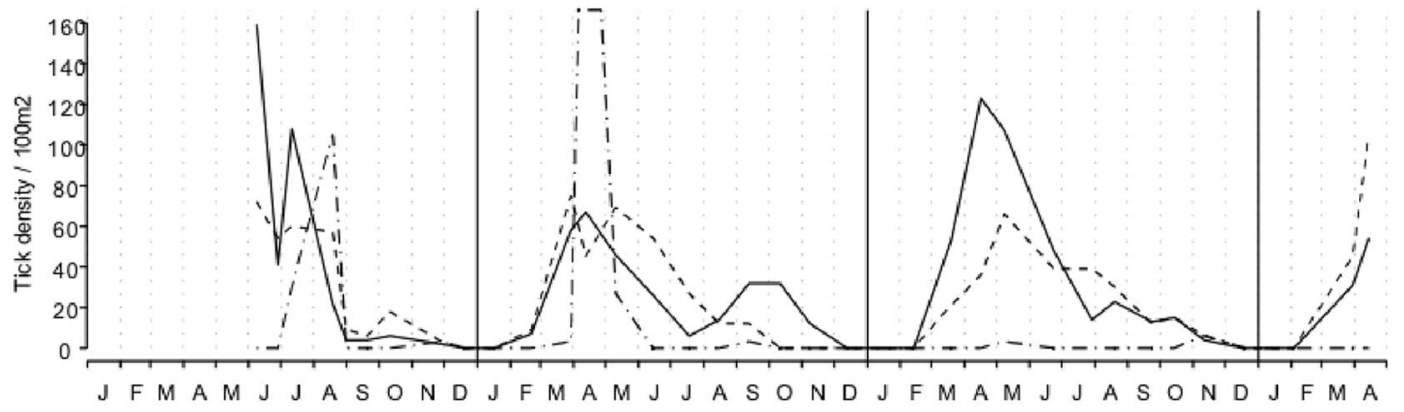

\section{Trimstein}

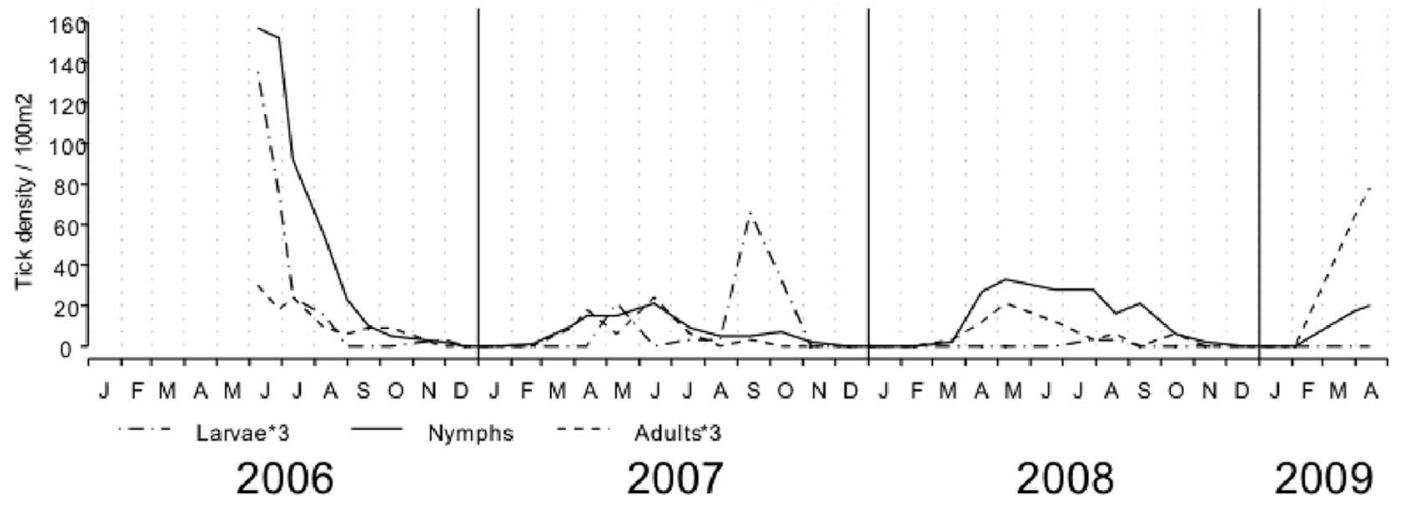

Fig. 1. Seasonality of questing tick density (larvae, nymphs, adults) at Thun, Belp, Kiesen, and Trimstein. Density of larvae and adults was multiplied by 3 . 

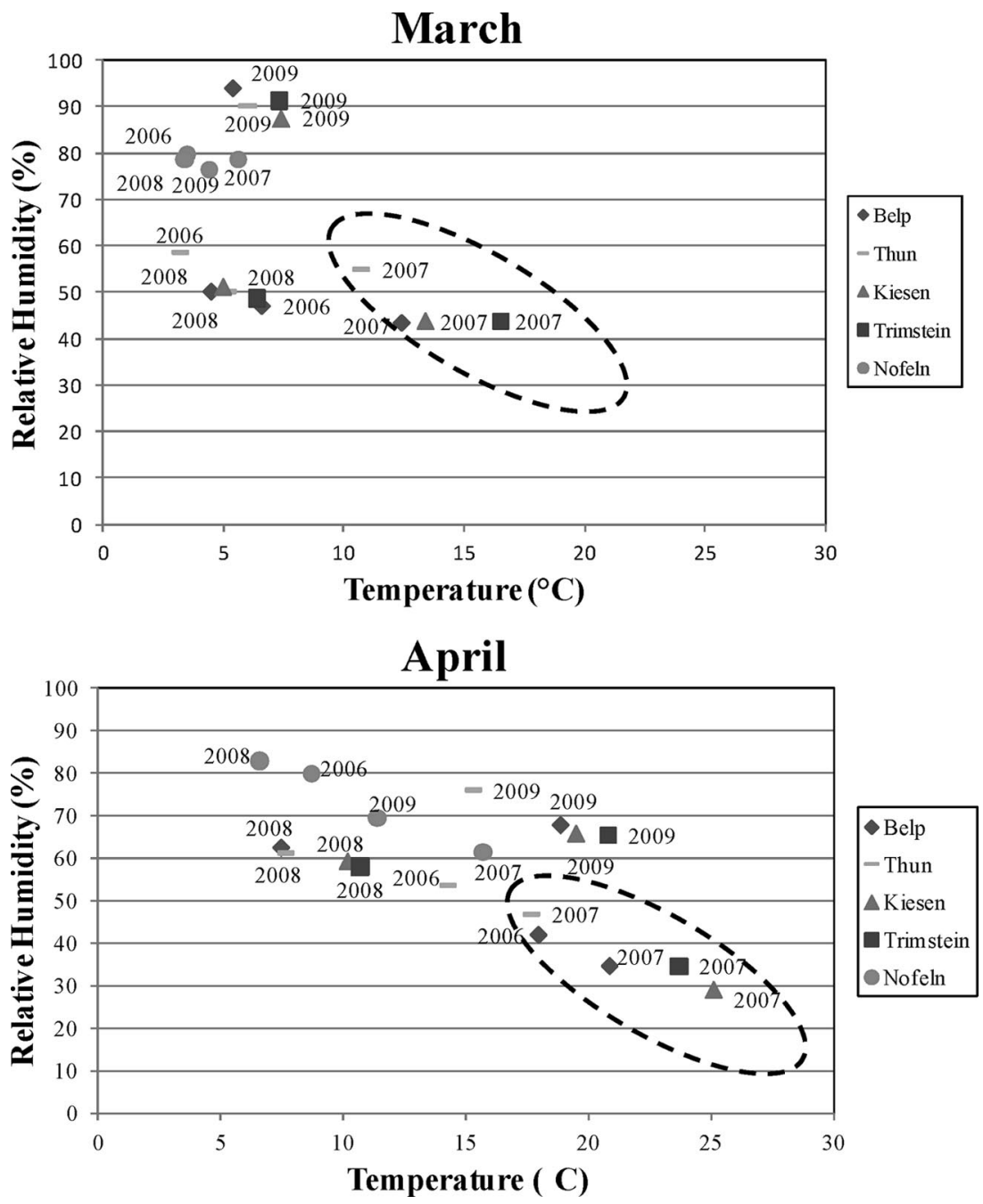

Fig. 2. Relative humidity (\%) in relation with temperature $\left({ }^{\circ} \mathrm{C}\right)$ at the four study sites in March and April 2006-2009. Macroclimatic data (Nofeln, monthly mean temperature, and monthly mean relative humidity) are shown to relate them to microclimatic data recorded at the study sites.

The prevalence of rodents infested by ticks at each study site did not differ significantly between 2007 and 2008 , except at Thun, where more rodents were infested by ticks in 2007 than $2008\left(\chi^{2}=3.9, \mathrm{df}=1, P=\right.$ 0.04) (Table 3). However, the intensity of tick infestation (mean number of ticks per infested host) during April to July (the months with the highest prevalence of infested rodents) was lower in 2007 than in 2008 at all sites except at Thun (Mann-Whitney $U$ test for larvae and nymphs together, $P=0.006$ for Kiesen; $P<$ 0.001 for Trimstein; $P=0.01$ for Belp) and was more pronounced for larvae than for nymphs (Table 4). Although more rodents were captured in 2007 (0.2 rodent/trap/night; $n=470)$ compared with 2008 (0.11 rodents $/$ trap/night; $n=241)$ ( $t$ test, $P=0.001)$, the total number of feeding nymphs collected was lower in $2007(n=116)$ than in $2008(n=188)$.

There was a significant positive correlation between the number of I. ricinus larvae and nymphs infesting rodents $\left(\mathrm{r}_{\mathrm{s}}=0.472, P<0.01 ; n=819\right)$ (Fig. 5). Overall at all sites, $20 \%$ of rodents were infested by nymphs; $9.3 \%$ (76/819) carried only one nymph, and 9.4\% (77/ 819) carried more than one nymph. Among sites, 13$27 \%$ most heavily infested hosts ( $>15$ larvae) fed 52 $84 \%$ of nymphs and $58-81 \%$ of larvae, the lowest value always corresponding to Trimstein and the highest to Kiesen (Fig. 5). Cofeeding ticks on rodents were usually observed from March to October (once observed in November), with a higher frequency from April to July (Fig. 4). During April to July 2007, a significantly lower proportion of hosts with cofeeding ticks was observed among infested hosts compared with the same period in 2008 at Belp and Kiesen (Table 4).

At Trimstein, tick infestation of rodents was different from the other sites. The proportion of rodents with cofeeding ticks among infested rodents was the lowest $(13.5 \%, 18 / 133)$ (Table 2$)$. At Trimstein, only 


\section{Thun}

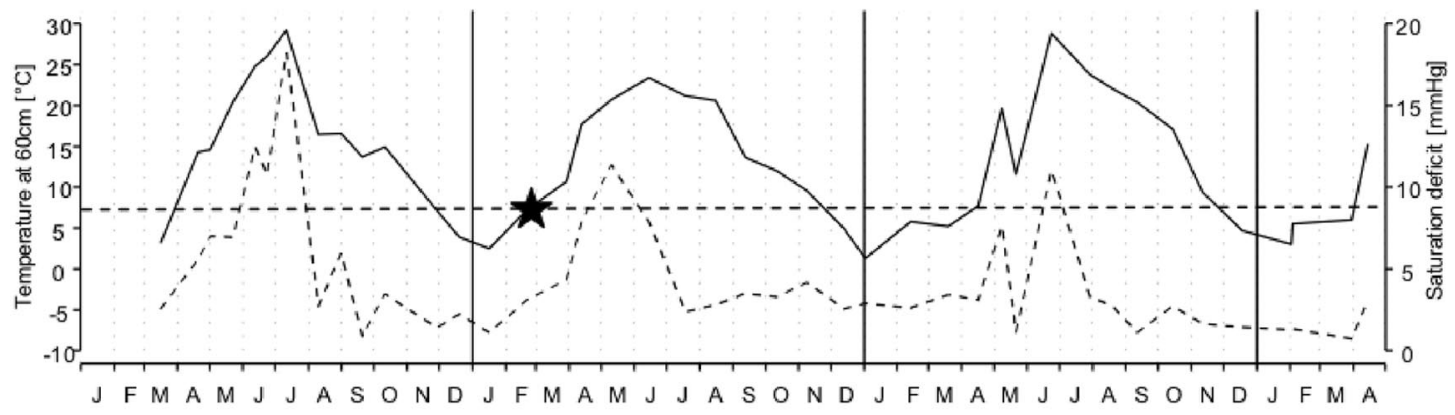

Belp

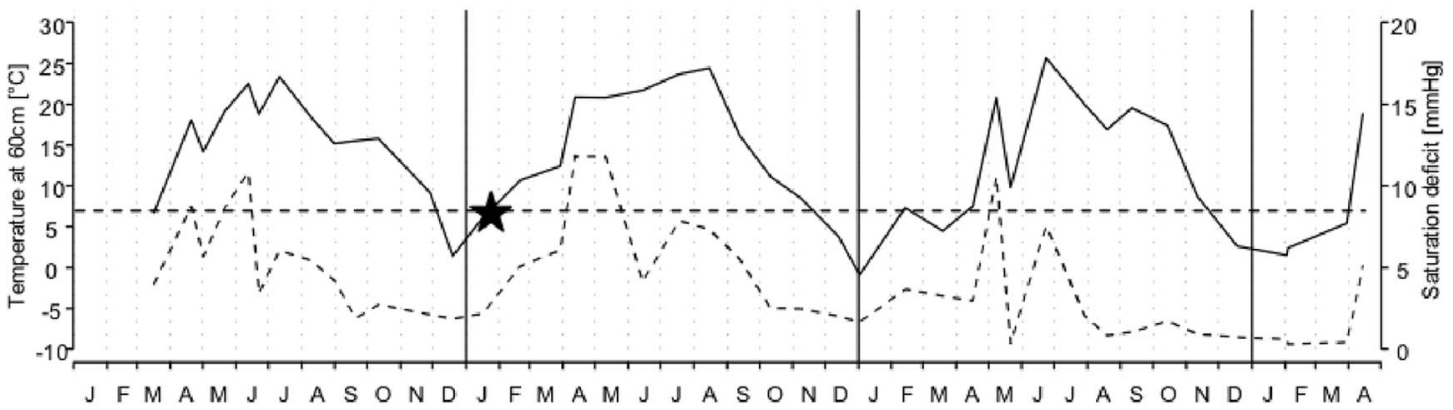

Kiesen

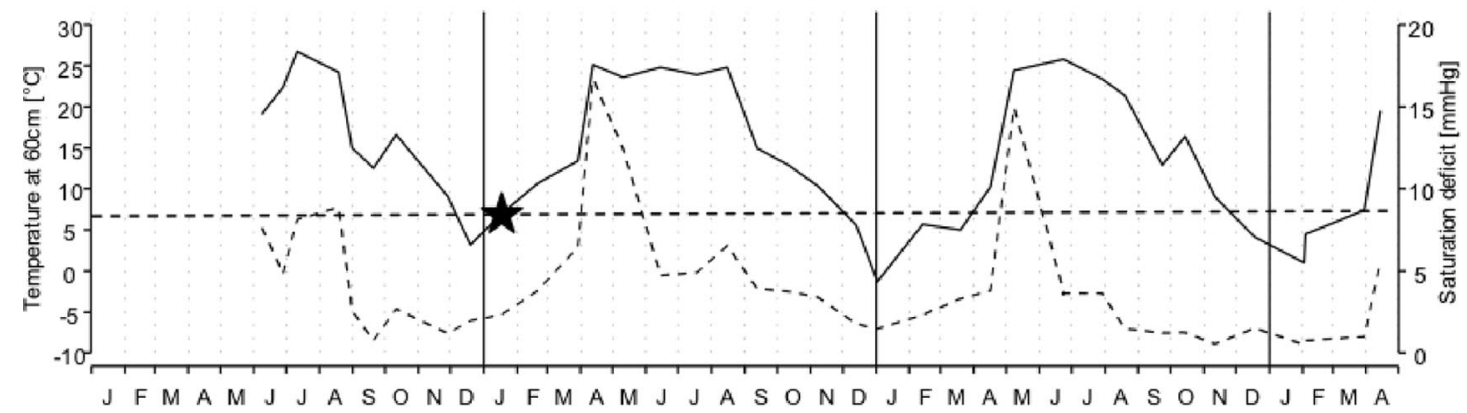

Trimstein

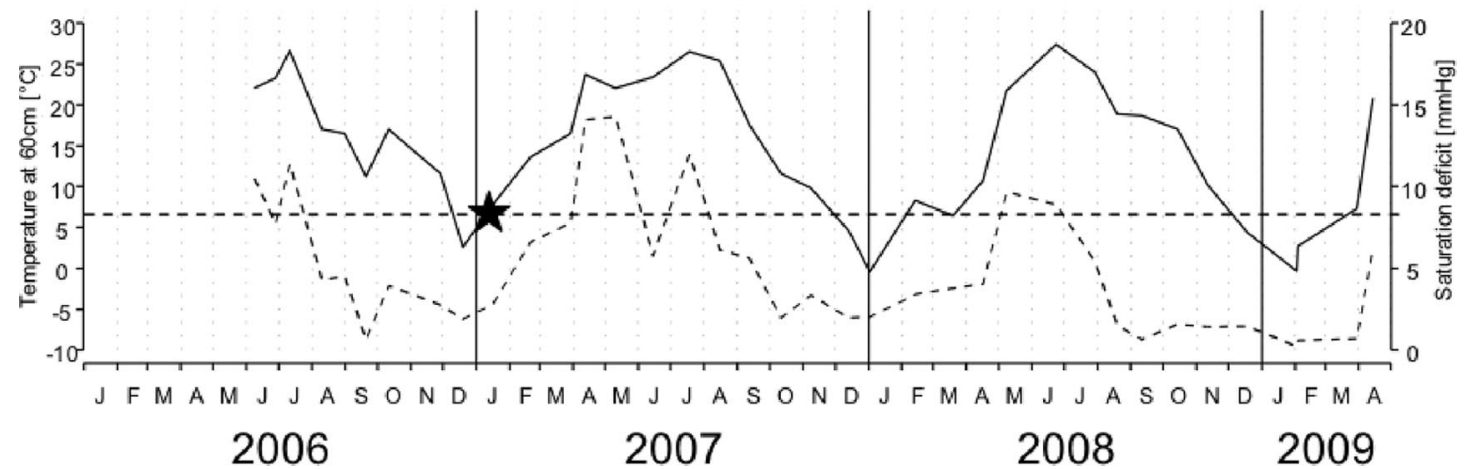

Fig. 3. Temperature at $60 \mathrm{~cm}\left({ }^{\circ} \mathrm{C},-\right)$ and saturation deficit $(\mathrm{mmHg},---)$ at all studied sites. Horizontal dotted lines represent the $7^{\circ} \mathrm{C}$, and stars show when temperature reached $7^{\circ} \mathrm{C}$ in 2007 . 
Table 1. Cumulative tick density and peak tick density for nymphs and adults at the four study sites per year

\begin{tabular}{|c|c|c|c|c|c|c|c|c|c|c|c|c|}
\hline \multirow{2}{*}{$\begin{array}{c}\text { Study } \\
\text { sites }\end{array}$} & \multicolumn{3}{|c|}{ CTD nymphs } & \multicolumn{3}{|c|}{ CTD adults } & \multicolumn{3}{|c|}{ PTD nymphs } & \multicolumn{3}{|c|}{ PTD adults } \\
\hline & 2006 & 2007 & 2008 & 2006 & 2007 & 2008 & 2006 & 2007 & 2008 & 2006 & 2007 & 2008 \\
\hline Thun & $1,463^{a}$ & 3,562 & 2,000 & $749^{a}$ & 482 & 1,032 & $21^{a}$ & 53 & 27 & $14^{a}$ & 6 & 14 \\
\hline Belp & $12,335^{a}$ & 3,720 & 6,234 & $1,794^{a}$ & 1,534 & 1,416 & $109^{a}$ & 31 & 59 & $31^{a}$ & 10 & 10 \\
\hline Kiesen & $18,566^{b}$ & 8,264 & 12,255 & $3,760^{b}$ & 2,911 & 2,752 & $159^{b}$ & 67 & 123 & $24^{b}$ & 25 & 22 \\
\hline Trimstein & $20,754^{b}$ & 2,627 & 4,994 & $1,444^{b}$ & 632 & 667 & $157^{b}$ & 21 & 33 & $10^{b}$ & 8 & 7 \\
\hline
\end{tabular}

CTD, cumulative tick density; PTD, peak tick density.

${ }^{a}$ Data collected from March.

${ }^{b}$ Data collected from June.

$15 \%$ (20/133) of infested rodents carried nymphs compared with $26.7 \%$ at Thun $(34 / 127), 37.8 \%$ at Belp $(39 / 103)$, and $35 \%$ at Kiesen (79/224) (Trimstein/ Thun, $\chi^{2}=4.74$, df $=1, P=0.02$; Trimstein/Belp, $\chi^{2}=$ 14.93, $\mathrm{df}=1, P<0.001$; Trimstein/Kiesen, $\chi^{2}=16.04$, df $=1, P<0.001)$. Nymphs represented only $2.4 \%$ $(14 / 576)$ of the total of ticks feeding on rodents from April to July 2007-2008, whereas they represented $4 \%$ $(28 / 703)$ at Belp, 5\% $(38 / 762)$ at Thun, and $6.9 \%$ $(162 / 2,336)$ at Kiesen. As a consequence, Trimstein showed the lowest ratio of nymphs/larvae on total hosts captured in 2007 and 2008 (1/60 and 1/34.5, respectively), whereas this ratio was $1 / 22.8$ and $1 / 10.9$ at Kiesen, $1 / 25.8$ and $1 / 14.6$ at Thun, and $1 / 44$ and 1/17.6 at Belp in 2007 and in 2008, respectively.

Molting success of blood-fed larval and nymphal ticks in the laboratory varied by year, with the lowest observed in 2007 (53\%, 1,566/2,969), followed by 2006 $(70 \%, 1,078 / 1,532)$ and $2008(77 \%, 2,081 / 2,692)\left(\chi^{2}=\right.$ 396 , $\mathrm{df}=2, P<0.001$ for years $)$. In 2007 , reduction in molting success was more evident for larvae $(48.7 \%$, $1,508 / 3,098)$ than for nymphs $(62 \%, 70 / 113)\left(\chi^{2}=\right.$ $7.16, \mathrm{df}=1, P=0.007)$. Molting was more frequent for Ixodes larvae $(69 \%, 2,325 / 3,393)$ and nymphs $(63 \%$, 102/161) collected from Apodemus spp. than from $M$. glareolus (larvae, 65\%, 2,286/3,525; nymphs, 49\%, 112/ 227) $\left(\chi^{2}=10.3\right.$, df $=1, P=0.001$ and $\chi^{2}=6.9$, df $=$ $1, P=0.009$, respectively).

Detection of TBEV in Ticks. A MIR of 0.1 positive ticks per 100 tested (95\% CI: $0.04-0.22$ ) was observed for 6,683 questing I. ricinus ticks tested for TBEV (4,833 nymphs in 514 pools, and 1,850 adults in 536 pools). TBEV was detected in ticks collected at the two known endemic sites, Thun and Belp, but also at Kiesen (Table 5). The only site where no TBEV was detected was Trimstein.

A MIR of 0.1 per 100 (95\% CI: 0.03-0.31) was detected in 3,303 I. ricinus ticks (3,090 larvae in 510 pools, and 213 nymphs in 132 pools) that detached from 435 rodents. TBEV was detected in ticks feeding on two males from Thun captured in April 2007 and 2008: one A. flavicollis was infested with five nymphs and 128 larvae, and one $M$. glareolus carried two nymphs and 14 larvae. TBEV was detected in $8.6 \%$ (3/35 [95\% CI: $1.8 ; 23.06])$ of larvae feeding on A. flavicollis and in $50 \%$ (one-half [95\% CI: $1.26 ; 98.74$ ] ) of larvae from the vole. Additional larvae feeding on the mouse was analyzed individually (as nymphs) and showed an infection rate of $11.9 \%(5 / 42)$. No I. trianguliceps $(n=$ 13) were infected.

Sequencing NS5 Protein Gene of TBEV. The NS5 gene amplified from cDNA of two infected larvae feeding on two rodents collected at Thun (GenBank accession HM450140 and HM450141) and the cDNA of four pools of questing adults from Thun $(n=2)$, from Belp $(n=1)$, and from Kiesen $(n=1)$ (GenBank accession HM450136, HM450137, HM450138, and HM450139, respectively) were sequenced. Target fragments from TBEV-infected questing ticks and from ticks feeding on rodents at Thun were $100 \%$ identical. The sequence obtained from the sample collected at Belp shared $99 \%$ of homology with those from Thun, but showed $98 \%$ homology with the one from Kiesen. The target fragments from ticks collected at Thun and Kiesen shared 99\% of homology. All sequences were $99 \%$ homologous with the Western subtype, TBEV of Slovenia NS5 sequence (GenBank accession EU057641.1).

Detection and Identification of Host DNA in Questing Nymphs. Overall, host DNA was amplified from $38.5 \%(274 / 712)$ questing nymphs. Of these, artiodactyls were identified as the main hosts for larval ticks $(34-53 \%)$ at each site (Table 6$)$. Bird DNA also was frequently detected in ticks from Belp $(35 \%, 26 / 74)$ and Trimstein $(35 \%, 25 / 72)$. Surprisingly, few small mammals were found to be important hosts for larvae, with $22 \%$ of detected DNA at Kiesen, $14.9 \%$ at Belp, and only $5.6 \%$ at Trimstein (Fisher test, $P=0.006$ for Kiesen, not significant for Belp) positive for small mammals. At Trimstein, larvae fed more frequently on

Table 2. Prevalence of rodents infested by ticks and by cofeeding ticks at the four study sites (2006-2009)

\begin{tabular}{|c|c|c|c|c|c|c|c|c|}
\hline & Thun & $P$ value & Belp & $P$ value & Kiesen & $P$ value & Trimstein & Total \\
\hline Infested/total rodents $(\%)$ & $127 / 169(75.1)$ & $0.03 *$ & $103 / 149(69.1)$ & 0.43 & $224 / 295(75.9)$ & $0.007^{*}$ & $133 / 206(64.5)$ & $587 / 819(71.7)$ \\
\hline $\begin{array}{l}\text { Infested with cofeeding } \\
\text { ticks/total infested } \\
\text { rodents }(\%)\end{array}$ & $33 / 127(26)$ & $0.017^{*}$ & 20/103 (19) & 0.3 & $74 / 223(33)$ & $<0.001^{*}$ & $18 / 133(13.5)$ & $145 / 586(24.7)$ \\
\hline
\end{tabular}

An asterisk indicates significant results $(P<0.05)$ when compared with results from Trimstein (Pearson $\chi^{2}$ test $)$. 

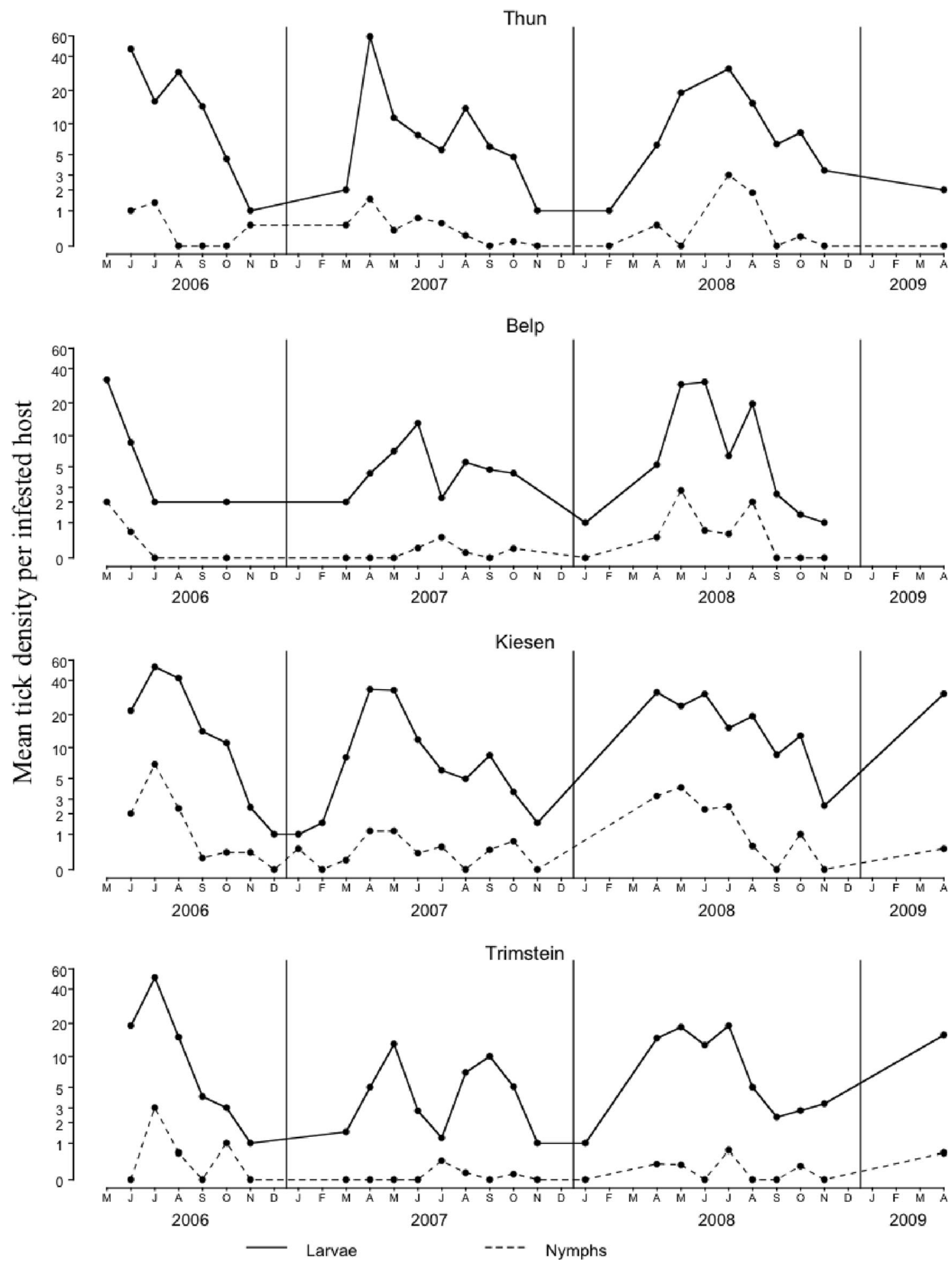

Fig. 4. Seasonality of mean tick density (log scale; larvae and nymphs) per infested host at the four study sites.

birds $(35 \%, 25 / 72)$ and artiodactyls $(46 \%, 33 / 72)$ than on small mammals $(5.6 \%, 4 / 72)$ (Fisher test, $P<0.001$ ). Small mammal DNA was less frequently detected in ticks in 2008 compared with 2006 at most sites (Table 6) (Fisher test, $P=0.037$ ), whereas the opposite was observed for bird DNA (Fisher test, $P=0.002$ ). 
Table 3. Prevalence of rodents infested by ticks according to years and sites

\begin{tabular}{lccrr}
\hline \hline \multirow{2}{*}{ Year } & \multicolumn{4}{c}{ No. infested/captured rodents $(\%)$} \\
\cline { 2 - 5 } & Thun & Belp & \multicolumn{1}{c}{ Kiesen } & Trimstein \\
\hline 2007 & $83 / 95(87)$ & $68 / 92(74)$ & $122 / 154(79)$ & $71 / 103(69)$ \\
2008 & $27 / 38(71)$ & $29 / 41(71)$ & $66 / 92(72)$ & $46 / 70(66)$ \\
\hline
\end{tabular}

\section{Discussion}

Influence of Microclimatic Conditions on Questing Tick Activity. During the study period, unusual microclimatic conditions were observed. Winter $2006-$ 2007 was very mild, and spring 2007 was hot and dry. This influenced questing tick phenology. Exceptionally mild temperatures during winter 2006-2007 allowed nymphs quest earlier (February) on vegetation. In Switzerland, studies on tick phenology showed that questing tick activity is usually the highest in spring (Jouda et al. 2004, Burri et al. 2007, Morán Cadenas et al. 2007b). However, in spring 2007, the questing nymph density was reduced at three sites (Belp, Trimstein, and Kiesen), but not at Thun. A possible explanation would be that nymphs had completed questing at these three sites and were blood feeding on hosts. However, in our case, the decrease in the questing nymph population paralleled the decrease in nymphs feeding on rodents, meaning that the absence of questing nymphs was not because of the attachment of ticks on rodents. An alternative explanation would be that nymphs may have been forced to interrupt their questing behavior to avoid desiccation and moved toward close to the soil to rehydrate as expected from the low RH and high SD values (Lees and Milne 1951; Perret et al. 2003, 2004). In such a case, nymphs that did not quest in spring would quest later in the year when microclimatic conditions were favorable. However, questing nymph density never increased and the CTD for nymphs remained low, indicating that the tick population may have suffered desiccation-related mortality because of the long-lasting high SD values during spring 2007 (Perret et al. 2000, 2004; Burri et al. 2007; Morán Cadenas et al. 2007b). Conversely, at Thun, questing nymph density was not altered during 2007. Microclimatic conditions in 2007 were more favorable for ticks at this site, and tick population did not appear to suffer from desiccation-related mortality.

Ticks on Rodents. The seasonal infestation pattern of rodents by larvae and nymphs did not match the seasonal questing activity of ticks. Larvae, and to a lesser extent nymphs, were observed on rodents almost each month from February-March to November, sometimes even during the winter months, whereas no ticks were collected by flagging. The fact that ticks were active on rodents during months without questing activity detected for ticks on vegetation questioned the risk assessment of tick bites on the human population primarily based on questing tick activity.

Because the coincident seasonal questing activity of I. ricinus larvae and nymphs is necessary to allow cofeeding transmission and maintain a TBEV focus (Labuda et al. 1993a, 1996, 1997; Randolph et al. 1996,

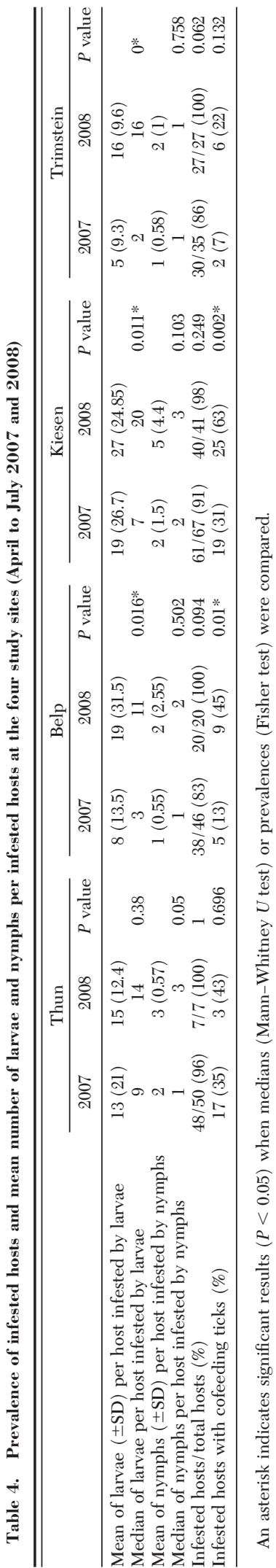



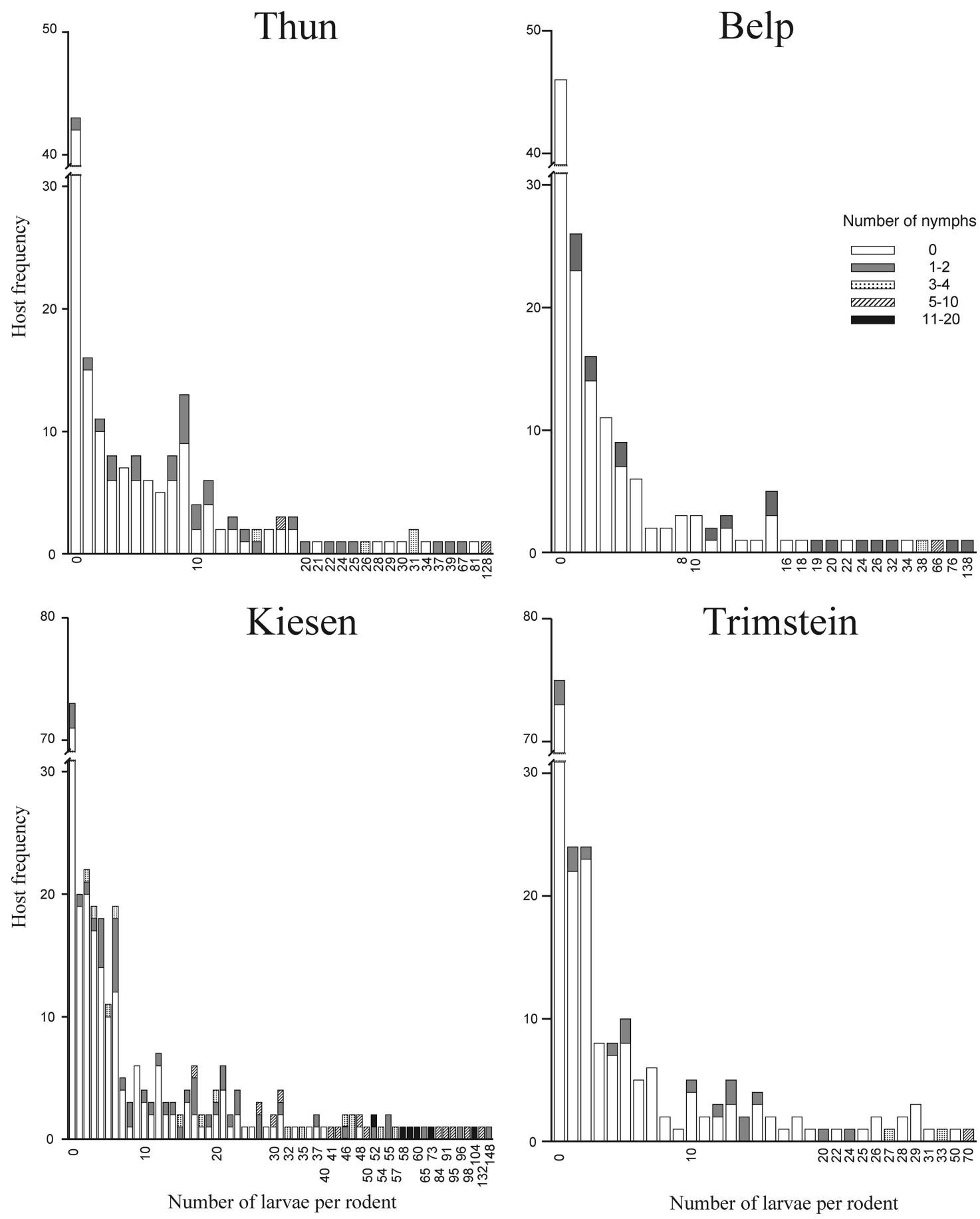

Fig. 5. Frequency distributions of I. ricinus larvae and nymphs on rodents (M. glareolus and Apodemus spp.) in 2006, 2007, and 2008. At each intensity of larval infestation ( $x$-axis), the number of hosts coincidentally feeding nymphs are shown.

1999), we investigated rodent infestation to better understand the role of cofeeding in TBEV maintenance. As mentioned above, exceptionally mild temperatures in winter 2006-2007 allowed an earlier questing of nymphs on vegetation; however, the cofeeding of larvae and nymphs on rodents did not appear early in 2007, prob- ably because in January and February the RH was high enough to allow nymphs quest on the upper parts of the vegetation and attach to medium-sized hosts rather than to rodents (Perret et al. 2004).

Although the percentage of rodents infested by ticks was generally stable over years, in 2007 we re- 
Table 5. Prevalence of TBEV in questing ticks at the four study sites

\begin{tabular}{|c|c|c|c|c|c|c|c|}
\hline \multirow{2}{*}{ Site } & \multirow{2}{*}{ Year } & \multicolumn{6}{|c|}{ No. infected/analyzed ticks ${ }^{a}$} \\
\hline & & Nymphs & $95 \% \mathrm{CI}^{b}$ & Adults & $95 \% \mathrm{CI}^{b}$ & Total & $95 \% \mathrm{CI}^{b}$ \\
\hline \multirow[t]{5}{*}{ Thun } & 2006 & $0 / 74(0)$ & $0-4.86$ & $0 / 42(0)$ & $0-8.41$ & $0 / 116(0)$ & $0-3.13$ \\
\hline & 2007 & $0 / 390(0)$ & $0-0.94$ & $2 / 156(1.3)$ & $0.16-4.55$ & $2 / 546(0.36)$ & $0.04-1.32$ \\
\hline & 2008 & $0 / 449(0)$ & $0-0.82$ & $0 / 182(0)$ & $0-2.01$ & $0 / 631(0)$ & $0-0.59$ \\
\hline & 2009 & 0/99 (0) & $0-3.66$ & $0 / 41(0)$ & $0-8.6$ & $0 / 140(0)$ & $0-2.6$ \\
\hline & $2006-2009$ & $0 / 1,012(0)$ & $0-0.36$ & $0 / 421(0)$ & $0-0.87$ & $2 / 1,433(0.14)$ & $0.02-0.5$ \\
\hline \multirow[t]{5}{*}{ Belp } & 2006 & $2 / 445(0.45)$ & $0.05-1.61$ & $0 / 75(0)$ & $0-4.8$ & $2 / 520(0.38)$ & $0.05-1.38$ \\
\hline & 2007 & $1 / 242(0.4)$ & $0.01-2.28$ & $0 / 241(0)$ & $0-1.52$ & $1 / 483(0.2)$ & $0.01-1.17$ \\
\hline & 2008 & $0 / 610(0)$ & $0-0.6$ & $1 / 160(0.6)$ & $0.02-3.44$ & $1 / 770(0.13)$ & $0.01-0.72$ \\
\hline & 2009 & $0 / 22(0)$ & $0-15.43$ & $0 / 8(0)$ & 0-36.94 & $0 / 30(0)$ & $0-11.57$ \\
\hline & 2006-2009 & $0 / 1,319(0)$ & $0-0.28$ & $0 / 484(0)$ & $0-0.76$ & $4 / 1,803(0.2)$ & $0.06-0.57$ \\
\hline \multirow[t]{5}{*}{ Kiesen } & 2006 & $0 / 297(0)$ & $0-1.24$ & $0 / 97(0)$ & $0-3.73$ & $0 / 394(0)$ & $0-0.93$ \\
\hline & 2007 & $0 / 567(0)$ & $0-0.65$ & $0 / 318(0)$ & $0-1.15$ & $0 / 885(0)$ & $0-0.42$ \\
\hline & 2008 & $0 / 539(0)$ & $0-0.68$ & $0 / 203(0)$ & $0-1.8$ & $0 / 742(0)$ & $0-0.5$ \\
\hline & 2009 & $0 / 186(0)$ & $0-1.97$ & $1 / 118(0.8)$ & $0.02-4.63$ & $1 / 304(0.33)$ & $0.01-1.82$ \\
\hline & $2006-2009$ & $0 / 1,589(0)$ & $0-0.23$ & $0 / 736(0)$ & $0-0.5$ & $1 / 2,325(0.04)$ & $0-0.24$ \\
\hline \multirow[t]{5}{*}{ Trimstein } & 2006 & $0 / 349(0)$ & $0-1.05$ & $0 / 37(0)$ & $0-9.49$ & $0 / 386(0)$ & $0-0.95$ \\
\hline & 2007 & $0 / 185(0)$ & $0-1.97$ & $0 / 55(0)$ & $0-6.49$ & $0 / 240(0)$ & $0-1.52$ \\
\hline & 2008 & $0 / 296(0)$ & $0-1.24$ & $0 / 40(0)$ & $0-8.81$ & $0 / 336(0)$ & $0-1.09$ \\
\hline & 2009 & $0 / 83(0)$ & $0-4.35$ & $0 / 77(0)$ & $0-4.68$ & $0 / 160(0)$ & $0-2.28$ \\
\hline & 2006-2009 & $0 / 913(0)$ & $0-0.4$ & $0 / 209(0)$ & $0-1.75$ & $0 / 1,122(0)$ & $0-0.33$ \\
\hline
\end{tabular}

TBEV-infected ticks are shown in bold.

${ }^{a}$ Prevalence is expressed as the minimal infection rate per 100 ticks tested.

${ }^{b}$ Confidence interval $=95 \%$.

corded not only a small number of nymphs on rodents, but also a decrease in larval infestation intensity and in the proportion of hosts with cofeeding ticks at Belp, Trimstein, and Kiesen, but not at Thun. The observed decrease in questing tick density as a result of dry microclimatic conditions at these three sites in spring 2007 may have influenced contacts between ticks and rodents. Furthermore, the increased abundance of rodents in 2007 probably also contributed to lower tick intensity on hosts (Nosek and Grulich 1967, Rosà et al. 2007). In addition, it appeared that in 2007 larvae fed more frequently on birds than on rodents, according to the blood meal analysis of nymphs collected in 2008. The reason for this apparent shift in host selection remains unknown, but mild temperatures at the beginning of 2007 may have favored contacts between birds and larvae. The proportion of hosts identified was not very high in this study, because most nymphs were collected in spring. In fact in a similar study, host identification success was higher among ticks collected in autumn than in spring (Morán Cadenas et al. 2007a). At Thun the situation was different, in that not only questing nymph density, but also infestation intensity and the proportion of hosts with cofeeding ticks were not altered during 2007. At this site, microclimatic conditions were less harsh in spring 2007 than at the other sites, but nevertheless dryer. Therefore, tick populations did not suffer desiccation-related mortality and nymphs quested lower on vegetation, as expected when microclimatic conditions are dry (Randolph and Storey 1999), and were caught by rodents. In fact, proportion of rodents infested by ticks and by cofeeding ticks as well as the intensity of tick infestation did not decrease in 2007 at Thun.

Interestingly, molting success of ticks that detached from rodents was the lowest in 2007, especially for larvae. Although the reasons for this are unknown, we suggest that because of unfavorable microclimatic conditions in spring 2007, ticks spent more energy to avoid desiccation and encountered physiological difficulties processing the blood meal, leading to a reduction in molting success.

TBEV in Ticks. The presence of TBEV was confirmed at the two sites that were recognized as TBE foci before our study began. At Thun, TBEV was detected in $0.14 \%$ of questing adults. Previous studies reported infection rates of $0.65-0.8 \%$ (Matile 1984), 2.1\% (de Marval 1994), and $0.32 \%$ (Wicki et al. 2000), showing the continuous presence of the virus. At Belp, prevalences of TBEV in questing ticks $(0.13-0.38 \%)$ were similar to that reported by de Marval (1994), $0.56 \%$, but were much lower than what was observed by Casati et al. (2006)

Table 6. Detection and identification of host DNA in I. ricinus questing nymphs at the four study sites

\begin{tabular}{|c|c|c|c|c|c|c|c|}
\hline \multirow{2}{*}{ Host DNA } & \multirow{2}{*}{$\begin{array}{c}\text { Thun } \\
2008(\%)\end{array}$} & \multicolumn{2}{|c|}{ Belp } & \multicolumn{2}{|c|}{ Kiesen } & \multicolumn{2}{|c|}{ Trimstein } \\
\hline & & $2006(\%)$ & $2008(\%)$ & $2006(\%)$ & $2008(\%)$ & $2006(\%)$ & $2008(\%)$ \\
\hline Artiodactyls & $25(42)$ & $12(34)$ & $15(38)$ & $8(42)$ & $26(53)$ & $9(43)$ & $24(47)$ \\
\hline Small mammals & $3(5)$ & $9(26)$ & $2(5)$ & $7(37)$ & $8(16)$ & $0(0)$ & $4(8)$ \\
\hline Birds & $6(10)$ & $9(26)$ & $17(44)$ & $0(0)$ & $10(20)$ & $3(14)$ & $22(43)$ \\
\hline Sciurus & $9(15)$ & $2(6)$ & $2(5)$ & $1(5)$ & $1(2)$ & $7(33)$ & $0(0)$ \\
\hline Carnivores (Vulpes, Meles) & $12(20)$ & $2(6)$ & $0(0)$ & $2(11)$ & $1(2)$ & $0(0)$ & $1(2)$ \\
\hline Insectivores (Sorex, Neomys) & $5(8)$ & $0(0)$ & $1(0)$ & $1(5)$ & $2(4)$ & $1(5)$ & $0(0)$ \\
\hline Others (Lepus, Lizard) & $0(0)$ & $1(3)$ & $3(8)$ & $0(0)$ & $1(2)$ & $1(5)$ & $0(0)$ \\
\hline $\begin{array}{l}\text { Identified host DNA/analyzed } \\
\text { ticks }\end{array}$ & $60 / 102(59)$ & $35 / 103(34)$ & $39 / 100(39)$ & $19 / 82(23)$ & $49 / 123(40)$ & $21 / 101(21)$ & $51 / 101(50)$ \\
\hline
\end{tabular}


(14.3\%) close to our collection site. Labuda et al. (2002) also reported high prevalence (14\%) in questing ticks in Slovakia and suggested that some specific geographic areas have high TBEV activity. Nevertheless, the overall TBEV prevalence observed in this study $(0.04-0.2 \%)$ fits with European and Swiss data ranging from 0.1 to $5 \%$ (Süss et al. 2003, Gäumann et al. 2010).

No human TBE cases have been reported from Kiesen and Trimstein, but we detected TBEV in questing ticks at Kiesen. This site appeared to be favorable for the maintenance of a TBEV focus. In agreement, nymphs represented $6.9 \%$ of the ticks feeding on rodents, and this area had the highest ratio nymphs/larvae on rodents. In addition, Kiesen displayed the highest proportion of hosts with cofeeding ticks and the highest mean intensity of ticks feeding on rodents, both enabling the enzootic transmission and maintenance of TBEV.

TBEV was not detected at Trimstein. Compared with a TBEV focus such as Thun, Trimstein showed a higher questing nymph density, indicating that TBEV maintenance does not seem to be related to tick abundance. The ratio of nymphs/larvae on rodents was the lowest (1:60 in 2007, and 1:34.5 in 2008), but this alone did not explain the absence of TBEV, because an even lower ratio (1: 100) was reported in Alsace (France) (see Randolph and Storey 1999), and TBEV is nevertheless maintained in that region. At Trimstein, the percentage of rodents infested by at least one tick stage was low, and only $15 \%$ of rodents carried nymphs. The proportion of rodents with cofeeding ticks was the lowest recorded (13.5\%) (Kiesen, 33\%; Thun, 26\%; Belp, 19\%), although there was no significant difference between Trimstein and Belp, probably because at Belp microclimatic conditions in 2007 significantly reduced the proportion of hosts with cofeeding ticks compared with 2008. In addition, blood meal analysis results revealed that larvae rarely fed on rodents at Trimstein (5.6\%), but preferred to feed on birds and artiodactyls. These hosts are not considered as reservoirs for TBEV and are not known to support cofeeding transmission (Labuda and Randolph 1999). These factors may have contributed to the absence of TBEV activity detected at this site.

In the current study, ticks that detached from rodents were also screened for TBEV. The virus was detected in larvae, but not in nymphs, infesting two rodents from Thun. Two explanations can be offered, as follows: either larvae had been transovarially infected or cofeeding transmission occurred between infected nymphs that had dropped off from rodents before their capture. Because one rodent was infested by a large number of larvae, some ticks could be analyzed individually. For the first time, we report on TBEV infection in larvae (11.9\%) feeding on rodents under natural conditions and tested individually.

\section{Conclusion}

Focal warm and dry microclimatic conditions reduced questing tick density, the proportion of hosts with cofeeding larval and nymphal ticks, and therefore enzootic TBEV transmission efficiency. Indeed, if sustained high temperature and low RH persist for con- secutive springs, a focal maintenance of TBEV could be disrupted in the absence of cofeeding nonviremic transmission, as predicted by Randolph (2001). In agreement, our only study site without TBEV detected was the site where the proportion of rodent hosts with cofeeding ticks was lowest.

\section{Acknowledgments}

This work is part of the Ph.D. thesis of Caroline Burri, and is catalogued by the EDEN Steering Committee as EDEN0240 (www.eden-fp6project.net) and was supported by the Swiss National Science Foundation (FN n $320000-$ 113936). We are thankful to Jacqueline Moret (University of Neuchâtel, Switzerland) and Guillaume Cailleau (Faculty of Geosciences and Environment, University of Lausanne, Switzerland) for great help in statistics and drawing of graphics; Francisca Morán Cadenas, Véronique Douet (Institute of Biology, University of Neuchâtel, Switzerland), Nataša Knap (Institute of Microbiology and immunology, University of Ljubljana, Slovenija), Katarína Ustaníková, and Elena Elečková (Institute of Virology, University of Bratislava, Slovakia) for valuable advice and help; and Philippe de Mendonça (Institut für vergleichende Tropenmedizin und Parasitologie, München, Germany) for the positive control. We also address special thanks to Olivier Rais, Maude Sunier, and Lucia García for technical assistance (Institute of Biology, University of Neuchâtel, Neuchâtel, Switzerland).

\section{References Cited}

Burri, C., F. Morán Cadenas, V. Douet, J. Moret, and L. Gern. 2007. Ixodes ricinus density and infection prevalence of Borrelia burgdorferi sensu lato along a North-facing altitudinal gradient in the Rhone Valley (Switzerland). Vector Borne Zoonotic Dis. 7: 50-58.

Casati, S., L. Gern, and J. C. Piffaretti. 2006. Diversity of the population of tick-borne encephalitis virus infecting $I x$ odes ricinus ticks in an endemic area of central Switzerland (Canton Bern). J. Gen. Virol. 87: 2235-2241.

Chomczynski, P., and N. Sacchi. 1987. Single-step method of RNA isolation by acid guanidinium thiocyanate-phenol-chloroform extraction. Anal. Biochem. 162: 156-159.

de Marval, F. 1994. Etude séroépidémiologique de l'encéphalite à tiques et de la borréliose de Lyme en Suisse. M.S. thesis, University of Neuchâtel, Neuchâtel, Switzerland.

Dumpis, U., D. Crook, and J. Oksi. 1999. Tick-borne encephalitis. Clin. Infect. Dis. 28: 882-890.

Eisen, R. J., L. Eisen, M. B. Castro, and R. S. Lane. 2003. Environmentally related variability in risk of exposure to Lyme disease spirochetes in northern California: effect of climatic conditions and habitat type. Environ. Entomol. 32: $1010-1018$.

Gäumann, R., K. Mühlemann, M. Strasser, and C. Beuret. 2010. High throughput procedure for tick surveys of tickborne encephalitis virus and its application in a national surveillance study in Switzerland. Appl. Environ. Microbiol. 76: 4241-4249.

Humair, P. F., V. Douet, F. Morán Cadenas, L. M. Schouls, I. Van De Pol, and L. Gern. 2007. Molecular identification of bloodmeal source in Ixodes ricinus ticks using $12 \mathrm{~S}$ rDNA as a genetic marker. J. Med. Entomol. 44: 869-880.

Jouda, F., J. L. Perret, and L. Gern. 2004. Ixodes ricinus density, and distribution and prevalence of Borrelia burgdorferi sensu lato infection along an altitudinal gradient. J. Med. Entomol. 41: 162-169. 
Kozuch, O., S. P. Chunikhin, M. Gresikova, J. Nosek, V. B. Kurenkov, and J. Lysy. 1981. Experimental characteristics of viraemia caused by two strains of tick-borne encephalitis virus in small rodents. Acta Virol. 25: 219-224.

Labuda, M., and S. E. Randolph. 1999. Survival strategy of tick-borne encephalitis virus: cellular basis and environmental determinants. Zentralbl Bakteriol. 289: 513-524.

Labuda, M., L. D. Jones, T. Williams, and P. A. Nuttall. 1993a. Enhancement of tick-borne encephalitis virus transmission by tick salivary gland extracts. Med. Vet. Entomol. 7: 193-196.

Labuda, M., P. A. Nuttall, O. Kozuch, E. Eleckova, T. Williams, E. Zuffova, and A. Sabo. 1993b. Non-viraemic transmission of tick-borne encephalitis virus: a mechanism for arbovirus survival in nature. Experientia 49: 802-805.

Labuda, M., J. M. Austyn, E. Zuffova, O. Kozuch, N. Fuchsberger, J. Lysy, and P. A. Nuttall. 1996. Importance of localized skin infection in tick-borne encephalitis virus transmission. Virology 219: 357-366.

Labuda, M., O. Kozuch, E. Zuffova, E. Eleckova, R. S. Hails, and P. A. Nuttall. 1997. Tick-borne encephalitis virus transmission between ticks cofeeding on specific immune natural rodent hosts. Virology 235: 138-143.

Labuda, M., E. Eleckova, M. Lickova, and A. Sabo. 2002. Tick-borne encephalitis virus foci in Slovakia. Int. J. Med. Microbiol. 291 Suppl. 33: 43-47.

Lees, A. D., and A. D. Milne. 1951. The seasonal and diurnal activities of individual sheep ticks (Ixodes ricinus L.). Parasitology 41: 189-208.

MacLeod, J. 1939. The seasonal and annual incidence of the sheep tick, Ixodes ricinus, in Britain. Bull. Entomol. Res. 30: 103-118.

Matile, H. 1984. Etude virologique et épidémiologique sur l'encéphalite à tiques en Suisse. M.S. thesis, University of Neuchâtel, Neuchâtel, Switzerland.

Morán Cadenas, F., O. Rais, P. F. Humair, V. Douet, J. Moret, and L. Gern. 2007a. Identification of host bloodmeal source and Borrelia burgdorferi sensu lato in field-collected Ixodes ricinus ticks in Chaumont (Switzerland). J. Med. Entomol. 44: 1109-1117.

Morán Cadenas, F., O. Rais, F. Jouda, V. Douet, P. F. Humair, J. Moret, and L. Gern. 2007b. Phenology of Ixodes ricinus and infection with Borrelia burgdorferi sensu lato along a north- and south-facing altitudinal gradient on Chaumont Mountain, Switzerland. J. Med. Entomol. 44: 683-693.

Nosek, J., and I. Grulich. 1967. The relationship between the tick-borne encephalitis virus and the ticks and mammals of the Tribec mountain range. Bull. W.H.O. 36(Suppl. 1): 31-47.

Pavlovsky, E. 1947. Ticks and tick-borne encephalitis (in Russian). Parazitologia Dalnego Vostoka Leningrad 5: 212-264.

Perret, J. L., E. Guigoz, O. Rais, and L. Gern. 2000. Influence of saturation deficit and temperature on Ixodes ricinus tick questing activity in a Lyme borreliosis-endemic area (Switzerland). Parasitol. Res. 86: 554-557.

Perret, J. L., P. M. Guerin, P. A. Diehl, M. Vlimant, and L. Gern. 2003. Darkness induces mobility, and saturation deficit limits questing duration, in the tick Ixodes ricinus. J. Exp. Biol. 206: 1809-1815.
Perret, J. L., O. Rais, and L. Gern. 2004. Influence of climate on the proportion of Ixodes ricinus nymphs and adults questing in a tick population. J. Med. Entomol. 41: 361-365.

Puchhammer-Stockl, E., C. Kunz, C. W. Mandl, and F. X. Heinz. 1995. Identification of tick-borne encephalitis virus ribonucleic acid in tick suspensions and in clinical specimens by a reverse transcription-nested polymerase chain reaction assay. Clin. Diagn. Virol. 4: 321-326.

Randolph, S. E. 2001. The shifting landscape of tick-borne zoonoses: tick-borne encephalitis and Lyme borreliosis in Europe. Philos. Trans. R. Soc. Lond. B Biol. Sci. 356: $1045-1056$.

Randolph, S. E. 2004. Evidence that climate change has caused 'emergence' of tick-borne diseases in Europe? Int. J. Med. Microbiol. 293(Suppl. 37): 5-15.

Randolph, S. E., and K. Storey. 1999. Impact of microclimate on immature tick-rodent host interactions (Acari: Ixodidae): implications for parasite transmission. J. Med. Entomol. 36: 741-748.

Randolph, S. E., L. Gern, and P. A. Nuttall. 1996. Co-feeding ticks: epidemiological significance for tick-borne pathogen transmission. Parasitol. Today 12: 472-479.

Randolph, S. E., D. Miklisova, J. Lysy, D. J. Rogers, and M. Labuda. 1999. Incidence from coincidence: patterns of tick infestations on rodents facilitate transmission of tickborne encephalitis virus. Parasitology 118: 177-186.

Rosà, R., A. Pugliese, M. Ghosh, S. E. Perkins, and A. Rizzoli. 2007. Temporal variation of Ixodes ricinus intensity on the rodent host Apodemus flavicollis in relation to local climate and host dynamics. Vector Borne Zoonotic Dis. 7: 285-295.

Saksida, A., D. Duh, S. Lotric-Furlan, F. Strle, M. Petrovec, and T. Avsic-Zupanc. 2005. The importance of tick-borne encephalitis virus RNA detection for early differential diagnosis of tick-borne encephalitis. J. Clin. Virol. 33: 331-335.

Schneider, H. 1931. Über epidemische akute Meningitis serosa. Wiener Klin. Wschr. 44: 350-352.

Schwaiger, M., and P. Cassinotti. 2003. Development of a quantitative real-time RT-PCR assay with internal control for the laboratory detection of tick-borne encephalitis virus (TBEV) RNA. J. Clin. Virol. 27: 136-145.

Süss, J. 2003. Epidemiology and ecology of TBE relevant to the production of effective vaccines. Vaccine 21 (Suppl. 1): S19-S35.

Tälleklint, L., and T. G. Jaenson. 1994. Transmission of Borrelia burgdorferi s.l. from mammal reservoirs to the primary vector of Lyme borreliosis, Ixodes ricinus (Acari: Ixodidae), in Sweden. J. Med. Entomol. 31: 880-886.

Wicki, R., P. Sauter, C. Mettler, A. Natsch, T. Enzler, N. Pusterla, P. Kuhnert, G. Egli, M. Bernasconi, R. Lienhard, H. Lutz, and C. M. Leutenegger. 2000. Swiss Army Survey in Switzerland to determine the prevalence of Francisella tularensis, members of the Ehrlichia phagocytophila genogroup, Borrelia burgdorferi sensu lato, and tickborne encephalitis virus in ticks. Eur. J. Clin. Microbiol. Infect. Dis. 19: 427-432.

Zilber, L. A. 1939. Spring-summer tick-borne encephalitis (in Russian). Arkhiv. Biol. Nauk. 56: 255-261.

Received 15 July 2010; accepted 13 November 2010. 